\title{
Planificación y evaluación del Trabajo de Fin de Grado:el caso del Grado en Información y Documentación de la Universidad Carlos III de Madrid
}

\author{
Virginia ORTIZ-REPISO \\ virginia@bib.uc3m.es \\ Carlos GARCÍA ZORITA \\ czorita@bib.uc3m.esv \\ Ana R. PACIOS \\ areyes@bib.uc3m.es \\ Marina VIANELLO \\ mvianello@bib.uc3m.es \\ Universidad Carlos III de Madrid. \\ Departamento de Biblioteconomía y Documentación
}

Recibido: Junio 2014

Aceptado: Noviembre 2014

Resumen: El Trabajo Fin de Grado (TFG) es, en el marco del Espacio Europeo de Educación Superior (EEES), y en particular en los estudios de Grado que oferta la Universidad Carlos III de Madrid, una asignatura más dentro del plan de estudios. Consiste en la realización de un trabajo de carácter individual, en el que el alumno demuestra los conocimientos, habilidades y competencias adquiridos durante sus estudios a un problema específico del ámbito de la titulación. La planificación, desarrollo y evaluación de esta asignatura supone diseñar instrumentos ad hoc que permitan valorar adecuadamente la adquisición de las competencias específicas ligadas al título de Grado al que opta el alumno. A tal efecto, en este trabajo, se presentan tres herramientas concretas que se han elaborado para el título de Grado en Información y Documentación que se imparte en la Universidad Carlos III de Madrid desde el curso 2008-09: un manual de orientación, un plan de avances y una rúbrica o matriz de evaluación. El primero de ellos, el manual de orientación, ofrece al estudiante una guía clara y precisa de cómo elaborar el trabajo. El segundo, el plan de avances, ha permitido desarrollar un procedimiento claro y unitario para todos los estudiantes y realizar un seguimiento adecuado de los avances de los alumnos con plazos temporales determinados. El tercero, la rúbrica o matriz de evaluación, ha facilitado una herramienta coherente y objetiva de calificación para los tribunales que los evalúan. Todas ellas permiten, tanto a los profesores como a los alumnos, realizar un seguimiento adecuado de los trabajos y una evaluación coherente y objetiva para todos ellos de las 16 competencias asociadas al TFG en el Grado en Información y Documentación con la correspondiente ponderación de sus indicadores.

Palabras clave: Educación basada en competencias; Espacio Europeo de Educación Superior; Educación Superior; Trabajo de Fin de Grado; Grados. 


\title{
Planning and evaluating undergraduate dissertations: an experience at the Carlos III University Bachelor's Degree in Information and Documentation
}

\begin{abstract}
In the framework of the European Higher Education Area, the Undergraduate Dissertation is a subject on the official curriculum for the bachelor's degrees that can be earned in Spanish universities, Carlos III University of Madrid among them. It consists of an individual dissertation in which students apply the knowledge, skills and competencies acquired throughout their 4-year courses to a problem specific to the discipline associated with the degree to which they aspire. Planning, conducting and evaluating the work involved in the dissertation call for ad hoc tools that must be designed to accurately appraise the command of specific competencies associated with the degree sought by the student. The present paper introduces three such tools developed for the Bachelor's Degree in Information and Documentation offered at Carlos III University since 2008-09: a guidance manual, a preview system and an evaluation rubric. The guidance manual provides students with clear and precise instructions on how to undertake their study. The preview system affords a consistent, clear procedure for all students and for suitable monitoring of their progress at specified intervals. The evaluation rubric is a consistent and objective marking tool for juries. The three enable students and staff to suitably monitor progress and for professors to consistently and objectively evaluate all students in accordance with the duly weighted categories into which the competencies associated with the bachelor's degree in Information and Documentation are grouped.
\end{abstract}

Keywords: Competency-based education; European Area of Higher Education; EHEA; Spanish higher education; Undergraduate dissertations, Degree Dissertation; Bachelor's degrees.

\section{INTRODUCCIÓN}

Las universidades españolas ponen en marcha los estudios de Grado en el curso académico 2008-2009 para adecuarse al Real Decreto 1393/2007 de Ordenación de las enseñanzas universitarias oficiales (España, 2007) y, por ende, al Espacio Europeo de Educación Superior (EEES).

La adaptación al EEES originó debates que inicialmente se centraron en el diseño curricular y que se concretaron en "libros blancos" elaborados por áreas temáticas y con un amplio consenso nacional (e incluso internacional) entre las universidades. Una vez establecido el marco legal mencionado, estos "libros blancos" sirvieron de base a la elaboración de los diferentes planes de estudio. Este fue el caso del Libro Blanco del Grado en Información y Documentación (ANECA, 2004).

Aunque ha preocupado de forma general que el nuevo modelo imponga la necesidad de llevar a cabo adaptaciones metodológicas en la forma en que los profesores enseñan (Fernández Díaz, 2010) y, también, en la que los estudiantes aprenden, no ha habido un consenso general sobre ello. Cada universidad ha resuelto con su propia normativa cuestiones tales como el peso de la evaluación continua en los procesos finales de calificación, pero se ha ocupado poco de los instrumentos que deben emplearse. En nuestra opinión, entre las herramientas de 
evaluación siguen teniendo mucho peso las pruebas objetivas finales, eso sí, con un creciente auge de cuestionarios tipo test basados en las plataformas de aprendizaje, pero todas ellas siguen enfocadas a valorar objetivos de aprendizaje. Sin embargo, poco a poco, los profesores han sido más conscientes de la necesidad de evaluar en qué grado nuestros estudiantes adquieren las competencias que necesitaran para desempeñar su profesión. Esto supone un cambio metodológico importante en la forma en la que habrá que enseñar y evaluar. En este sentido, creemos que una de las novedades más significativas que han aportado los nuevos Grados, siguiendo las directrices del Real Decreto aludido (España, 2007), es la inclusión de un modo generalizado y con carácter obligatorio, de una asignatura final cuyo objeto es la elaboración de un trabajo de investigación, el "Trabajo fin de Grado" (en adelante, TFG). Debe elaborarse de forma escrita y defenderse, oralmente, ante un tribunal formado por tres profesores. En este trabajo se describe cómo se ha llevado a cabo el proceso de implantación y evaluación del TFG en el Grado de Información y Documentación de la Universidad Carlos III de Madrid.

Esta Universidad, fue la primera en España en adaptar todos sus estudios al EEES. Desde el primer año de implantación de los nuevos Grados, se ha venido ofertando a los egresados de las titulaciones antiguas, Diplomaturas, la posibilidad de adaptar su cualificación profesional al nuevo sistema de títulos. Para ello, se diseñaron cursos especiales denominados "Cursos de Adaptación al Grado" (en adelante CAG) con una carga lectiva de 60 ECTS. En el caso particular del CAG en Información y Documentación en la UC3M se ofertó en modalidad semipresencial.

Estos cursos se caracterizan porque los alumnos deben cursar una serie de asignaturas complementarias, que no han realizado en la Diplomatura ya extinta y que, en su mayor parte, pertenecen al Grado al que aspiran. Naturalmente, deben concluir con la elaboración y defensa de un TFG orientado a la evaluación de las competencias asociadas al título. En el marco del EEES, y en particular en los estudios de Grado de la Universidad Carlos III de Madrid, el TFG, según la normativa propia que lo regula desde el 2010, "es una materia dentro del plan de estudios que consiste en la realización de un trabajo de carácter individual en el que el alumno hace aplicación de los conocimientos, habilidades y competencias adquiridos durante sus estudios a un problema específico del ámbito de la titulación" (Universidad Carlos III, 2010). Se trata, por tanto, de un trabajo que debe tener la suficiente entidad como para permitir valorar las aptitudes y la idoneidad de los futuros graduados y en el que se demuestre, asimismo, la capacitación técnica y profesional. En definitiva, las competencias que han adquirido.

La gestión de esta asignatura, con una carga lectiva de 12 créditos, se viene realizando desde el curso 2008-2009. Desde entonces, se han tenido que elaborar criterios y procedimientos para regular y homogeneizar los trabajos presentados. Para ello, se contó con la experiencia de las antiguas titulaciones de ingeniería, en 
las que de un modo similar, para alcanzar la calificación profesional era necesario presentar un trabajo final denominado "proyecto de fin de carrera".

Algunos autores (Vilardell Riera, 2010) han hecho referencia a la escasez de bibliografía en el ámbito español, relacionada con la metodología y experiencias relativas a los TFG, dada su novedad. Sin embargo, desde el 2009 se han venido haciendo contribuciones en diferentes foros con el propósito de enfrentarse al reto que supone la dirección y planificación de esta asignatura académica en cualquier área de conocimiento (Andrés, 2009; Valderrama Vallés, 2009; Universitat Autonoma de Barcelona, 2010; Valderrama Vallés et al. 2010; Foro sobre la Evaluación de la Calidad de la Investigación y la Educación Superior, 2011). Asimismo han empezado a editarse guías y manuales para orientar en su elaboración (Ferrer, 2012; Fondevila, 2013)

\section{OBJETIVO DEL TRABAJO}

Las diferentes fases que están presentes en un TFG son: la planificación, el seguimiento, defensa y evaluación. Estas tres etapas implican tanto a los estudiantes como a los profesores, bien sean estos tutores o miembros evaluadores de los tribunales. El objetivo de este trabajo es dar a conocer la metodología y las herramientas de seguimiento y evaluación de la asignatura del TFG en el Grado en Información y Documentación de la Universidad Carlos III de Madrid. Esta experiencia que se presenta puede servir a otros grados y universidades a implantar herramientas similares para la gestión y evaluación de sus TFG.

En primer lugar, se expone el balance de los dos primeros años de su puesta en marcha así como las características que reunieron los trabajos presentados tanto en su elaboración, como en su seguimiento y evaluación. En segundo lugar, se presentan tres herramientas metodológicas: manual de orientación para el alumno; un plan de avances y una rúbrica o matriz de evaluación. Todas ellas se diseñaron con el objetivo de corregir las deficiencias y los errores detectados en los trabajos defendidos en estos dos primeros cursos. Por último, se analizan los resultados obtenidos hasta febrero de 2012. En un futuro próximo, se realizará una nueva evaluación de estas herramientas para corregir las debilidades que se detecten y mejorarlas.

\section{METODOLOGÍA}

Para conseguir estos objetivos, se ha llevado a cabo un estudio detallado de todos los TFGs defendidos durante dos cursos académicos, 2008-10, desde la implantación del Curso de Adaptación en el 2008/09 hasta el curso 2010/11, año en el que se empieza a aplicar la normativa propia de la universidad Carlos III para regular los TFGs. Este análisis ha permitido realizar un balance de los resultados 
obtenidos en relación, fundamentalmente, con las competencias que perseguía la asignatura. Se pretendió una doble valoración:

- Cualitativa, analizando si en cada uno de los trabajos presentados durante estos dos cursos académicos, se podía identificar cada una de las competencias que se establecieron en la normativa propia de la Universidad.

- Cuantitativa, ofreciendo el porcentaje relativo al nivel de cumplimiento de cada una de las competencias en el conjunto de los trabajos defendidos.

Asimismo, para conocer con más detalle el grado de consecución de dichas competencias, entrevistamos a los profesores/tutores para que indicaran las fortalezas y debilidades que detectaron en los trabajos, incluidos los problemas que los alumnos tuvieron durante el proceso de elaboración. Se analizaron también, las preguntas que formularon los propios alumnos, a través del foro dispuesto para tal fin en la plataforma docente utilizada en la Universidad (Moodle). Todo ello se ha tenido en cuenta en el diseño de las herramientas que se presentan con el objetivo de favorecer el cumplimiento de las competencias y que se están utilizando hasta el momento actual.

Para el análisis cuantitativo, tanto descriptivo como multivariable, se han utilizado las funciones implementadas en el basic package del software libre $\mathrm{R}(\mathrm{R}$ Development Core Team, 2011). Para el Análisis de los Componentes Principales (ACP), se utilizó la librería 'princomp' implementada en el stats package del mismo software.

\section{LA EVALUACIÓN POR COMPETENCIAS}

La enseñanza por competencias se ha ido imponiendo en los últimos tiempos. Su nacimiento tiene lugar en el ámbito laboral y hace referencia a todos aquellos aspectos (habilidades, destrezas, actitudes...) que debe poseer un profesional para desarrollar su labor de forma eficaz (Jornet Melia, 2011). Ahora bien, las competencias son, como sostienen Kerka (2008) y Carabaña Morales (2011), algo más que una mera lista de conductas o actitudes. Fundamentalmente suponen combinaciones complejas de conocimientos, actitudes, destrezas y valores que se hacen evidentes en la realización o desempeño de una tarea. Son, por tanto, compatibles con concepciones cognitivas del aprendizaje y con enfoques humanistas.

Algunos especialistas (Voorhees, 2001; Pimienta Prieto, 2011; Ribes Iñesta, 2011; Salvador Olilván, 2011) están a favor de utilizar la evaluación por competencias en los estudios universitarios. Incluso, en el caso particular de los estudios de Grado en Información y Documentación se han hecho contribuciones para facilitarla (Mano González, 2009). Sin embargo, otros autores plantean que si bien son útiles en la formación profesional, no lo son tan apropiadas en la educación superior (Carabaña Morales, 2011). Algunos expertos (Castro Morera, 2011) dudan 
además de la fiabilidad de las pruebas de competencias porque, incluso cuando se desarrollan guías de puntación muy claras y precisas, no dejan de ser subjetivas en $\mathrm{su}$ valoración. Aunque este debate es muy interesante, no podemos detenernos mucho en él ya que se escapa a los límites de este trabajo. Paulson (2001) ha publicado una interesante y completa bibliografía comentada sobre el tema.

Debemos resaltar que la docencia en la Universidad española, desde la creación del EEES (Martínez Berruezo, 2011) y el Proyecto Tuning tanto para Europa (Tuning, 2009) como para América Latina (Tuning, 2012) ha adoptado el enfoque basado en las competencias. Es, teniendo en cuenta esta realidad que se impone, lo que ha llevado a la Universidad Carlos III de Madrid a fijar las propias para el TFG y son, por tanto, el punto de partida para el desarrollo de la matriz de evaluación, del manual y de los mecanismos de seguimiento que se describen en este trabajo.

La Universidad reguló los TFGs para todas las titulaciones a partir del curso 2010-2011 mediante una Normativa (Universidad Carlos III, 2010) en la que se propuso un conjunto de competencias generales que deberían alcanzar todos los estudiantes al finalizar sus estudios y que conformarían su evaluación. Se empieza a aplicar a partir del curso 2010-2011.

Las competencias propuestas son las siguientes:

1. Capacidad de análisis y síntesis.

2. Capacidad de organizar y planificar.

3. Capacidad de abstracción y deducción.

4. Capacidad para generar nuevas ideas (creatividad).

5. Actitud crítica respecto a los conocimientos actuales.

6. Preocupación por la calidad y el trabajo bien hecho.

7. Preocupación por la repercusión de la actividad profesional en cuanto a su repercusión en el ámbito social, económico y medioambiental.

8. Compromiso cívico, ético y deontológico.

9. Aplicación de los conocimientos a situaciones diversas y en escenarios diferentes

10. Uso de las nuevas tecnologías para la búsqueda de información y documentación y de datos estadísticos.

11. Elección del marco conceptual adecuado para la resolución de un problema.

12. Aplicación de métodos cuantitativos y cualitativos apropiados a los datos disponibles o familiaridad para la obtención de datos a través de trabajos de campo.

13. Dominio del lenguaje y disciplina en su uso para un adecuado ejercicio de comunicación oral y escrita.

14. Buena disposición para la culminación individual de un proyecto.

15. Adaptación a nuevas situaciones y para anticipar y asimilar el cambio. 
16. Desarrollo de habilidades de aprendizaje y grado de confianza y autonomía adquirido.

Las cinco competencias específicas del TFG, enumeradas en la memoria Verifica del Grado en Información y Documentación, se recogen en las anteriormente indicadas. Específicamente coinciden con los números 1, 2, 3, 9 y 12. Aunque estaban expresadas de acuerdo con la naturaleza y objetivos propios del área de Biblioteconomía y Documentación no recogían todas las competencias de forma tan exhaustiva como las utilizadas.

Previa a la aplicación de esta normativa, en el Departamento de Biblioteconomía y Documentación se elaboró una normativa transitoria propia que proporcionaba un marco de actuación para su correcto funcionamiento. Esta normativa se tituló "Regulación transitoria de la asignatura Trabajo Fin de Grado en el Curso de Adaptación al Grado en Información y Documentación". Para su elaboración se tuvo en cuenta la normativa y regulación de los proyectos de fin de carrera de la Escuela Politécnica Superior de la Universidad Carlos III (2008).

Entre los aspectos que hay que destacar de la normativa transitoria estaban las modalidades a las que el alumno podía optar y las características que debía reunir el trabajo, así como el sistema de evaluación que se aplicaría. Respecto al primer punto, la elección del tema, se fijaron dos posibilidades: el alumno podía hacer una propuesta que tenía que ser avalada por un profesor o bien podía elegir entre el elenco de temas que propondrían los profesores del Departamento. El trabajo tenía que responder a una estructura fijada en el documento compuesta por una serie de elementos básicos: Índice, Introducción, Objetivos, Metodología, Desarrollo, Conclusiones y Bibliografía. Para la defensa oral ante el tribunal compuesto por tres profesores, se fijó un tiempo máximo de 30 minutos: 15 de exposición pública y otros 15 de debate con el tribunal. Para el Grado de Información y Documentación, en la calificación final del trabajo (sobre diez puntos) se establecieron los criterios y ponderación siguientes:

- $\quad$ Organización y estructura del trabajo (1 punto).

- $\quad$ Planteamiento del tema y aspectos formales (2 puntos).

- $\quad$ Contribución (1 punto).

- Conocimientos y contenido (3 puntos).

- $\quad$ Presentación y tono de la exposición (3 puntos).

En relación con el texto, se debía tener en cuenta: la presentación, originalidad, capacidad de relación y síntesis, metodología, coherencia de las conclusiones o resultados. Y, en cuanto a la defensa: la capacidad de comunicación y de síntesis, la estructuración de la presentación así como la capacidad de respuesta a las preguntas del tribunal. 
En los dos cursos académicos en los que se aplicó esta regulación, se presentaron y defendieron un total de 44 trabajos, el balance es el siguiente:

- Durante el curso 2008-09 se matricularon 43 alumnos, 42 eligieron uno de los 67 temas que propusieron los profesores y sólo uno hizo su propia propuesta. Se defendieron 18 trabajos. La nota media fue de 7,5.

- El curso 2009-10, también contó con 43 alumnos matriculados. Se ofertaron 34 nuevos temas para la realización del trabajo, a los que se añadieron los que no fueron elegidos el curso anterior. De los nuevos se eligieron todos y 9 alumnos hicieron su propia propuesta. Se defendieron 26 trabajos. La nota media fue 7,9.

- Aproximadamente un $52 \%$ de los alumnos matriculados no pudieron presentar y defender su TFG en el curso académico correspondiente. Necesitaron uno o dos cursos más para realizarlo.

La normativa que se aplicó no presentaba la evaluación por competencias en sentido estricto. Aunque estaba orientada a evaluar las competencias del título, no contaba con un procedimiento claro de aplicación.

Para realizar el balance de estos dos primeros cursos y verificar si los primeros TFGs cumplían con las 16 competencias establecidas posteriormente, se llevó a cabo un análisis cualitativo de todos los TFG defendidos en este periodo. Mediante la observación detallada de la estructura de los trabajos, sus contenidos y la bibliografía incluida se pudo valorar el grado de cumplimiento para cada una de las competencias establecidas. La calificación numérica final realmente obtenida por los estudiantes gracias a la valoración hecha por los tribunales correspondientes, utilizando el criterio transitorio descrito más arriba, no permitía conocer el nivel de adquisición de competencias. Esta valoración se llevó a cabo por los autores del presente trabajo que revisaron, de modo independiente y sin conocer la calificación real obtenida, los primeros 44 TFGs presentados.

En la tabla 1, se presenta el grado de cumplimiento obtenido por este método de evaluación a ciegas para cada una de las competencias establecidas en la rúbrica de evaluación. 
Tabla I. Presencia de competencias en los TFG realizados durante los cursos 2008-2010

\begin{tabular}{|c|c|}
\hline COMPETENCIA & CUMPLIMIENTO \\
\hline Capacidad de organizar y planificar & $77,3 \%$ \\
\hline Elección del marco conceptual adecuado & $67,0 \%$ \\
\hline Aplicación de métodos cuantitativos y cualitativos & $77,3 \%$ \\
\hline Preocupación por la calidad y el trabajo bien hecho & $83,0 \%$ \\
\hline Uso de las nuevas tecnologías & $78,4 \%$ \\
\hline Capacidad de análisis y síntesis & $62,5 \%$ \\
\hline Capacidad de abstracción y deducción & $69,3 \%$ \\
\hline Capacidad de generar nuevas ideas & $54,5 \%$ \\
\hline $\begin{array}{l}\text { Adaptación a nuevas situaciones para anticipar y asimilar el } \\
\text { cambio }\end{array}$ & $88,6 \%$ \\
\hline Buena disposición para la culminación del proyecto & $68,2 \%$ \\
\hline Preocupación por la repercusión de la actividad profesional... & $68,2 \%$ \\
\hline Compromiso cívico ético y deontológico & $75,0 \%$ \\
\hline Actitud crítica respecto a los conocimientos actuales & $69,3 \%$ \\
\hline Aplicación de los conocimientos a situaciones diversas & $93,2 \%$ \\
\hline Dominio del lenguaje y disciplina en su uso & $86,4 \%$ \\
\hline $\begin{array}{l}\text { Desarrollo de habilidades de aprendizaje y grado de confianza y } \\
\text { autonomía adquiridos }\end{array}$ & $68,2 \%$ \\
\hline
\end{tabular}

Una vez revisados todos los trabajos presentados, los datos revelaron que los estudiantes alcanzaron, en su conjunto, las competencias establecidas. Algunas de ellas fueron adquiridas en mayor medida que otras, especialmente aquellas que tienen que ver con habilidades procedimentales (planificación, metodología, estructura lógica, edición adecuada y uso de herramientas tecnológicas de ayuda como son los gestores bibliográficos). Sin embargo, había otras, cuya realización era más deficiente y afectan a las habilidades que atañen al marco conceptual del TFG y a las capacidades cognitivas (conceptualización del tema, tratamiento innovador, labor de análisis y síntesis, extrapolación de conclusiones, visión crítica del tema abordado, etc.).

Con objeto de verificar la consistencia de la reevaluación cualitativa llevada a cabo, se realizó una comparación entre las calificaciones reales obtenidas por los alumnos al defender su TFG y las asignadas por los autores de este trabajo mediante la evaluación a ciegas. La figura 1 muestra las distribuciones de ambas puntuaciones para cada uno de los estudiantes analizados. Los datos señalan que existe una gran correlación entre ambos sistemas de calificación (Coef. Cor. Pearson $=0.8634 ; \mathrm{t}=11.0894$, g.l. $=42$, $\mathrm{p}$-valor $<.05$ ) . 
Figura 1. Comparación de las puntuaciones reales y de la evaluación a ciegas de los 44 TFG

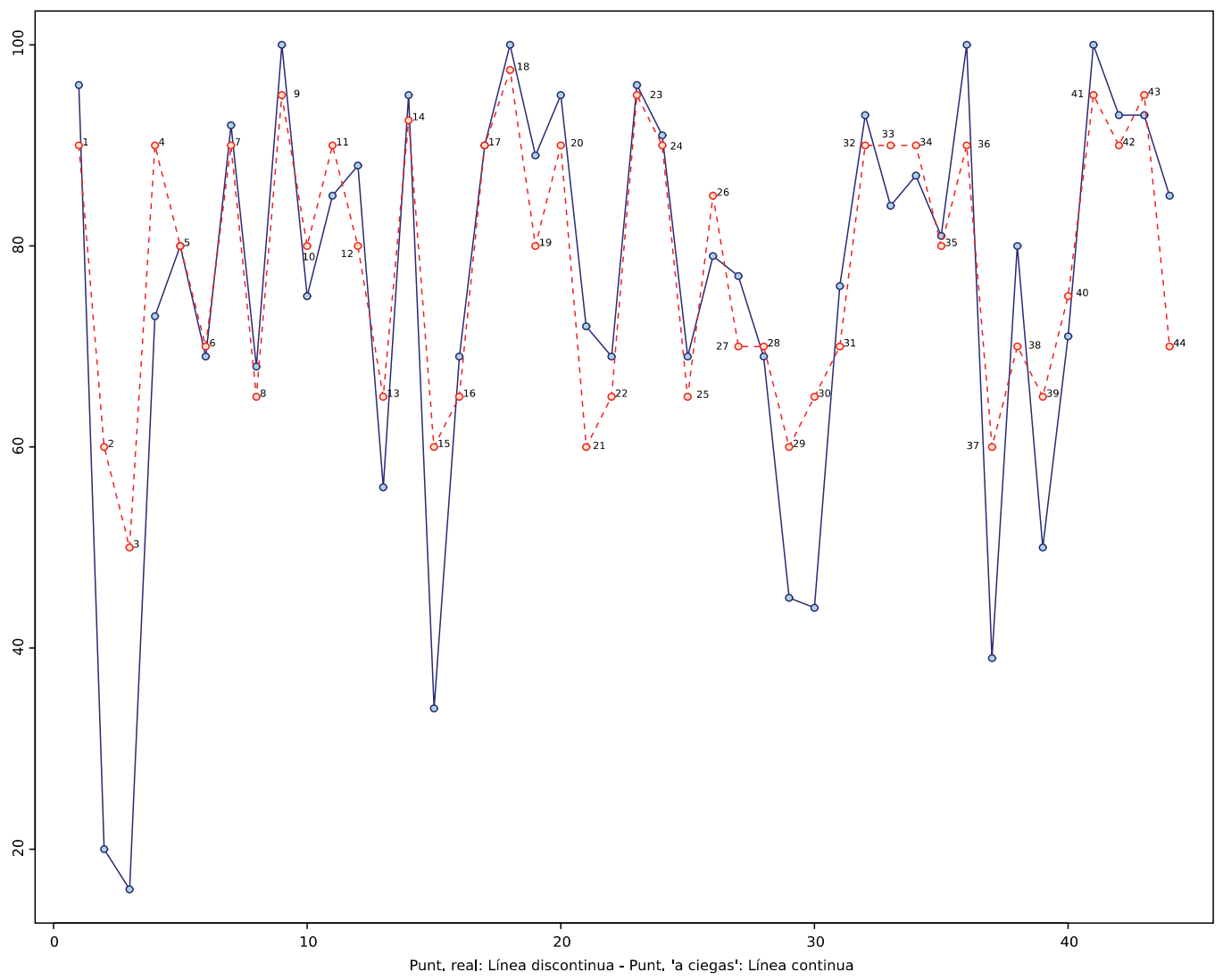

Complementariamente se resumen las características de dichas distribuciones representándolas mediante sendos gráficos tipo boxplot que se muestran en la figura 2. Ambas distribuciones tienen una variabilidad similar, como se puede apreciar por la amplitud de las "cajas", presentan el mismo valor para las medianas y valores cercanos para la media (75.75 para la evaluación a ciegas, 78.07 para la real). Únicamente en la distribución de las puntuaciones de la evaluación a ciegas se presentan dos estudiantes con valores atípicos. 
Figura 2. Boxplot de las distribuciones de las puntuaciones reales y "a ciegas"

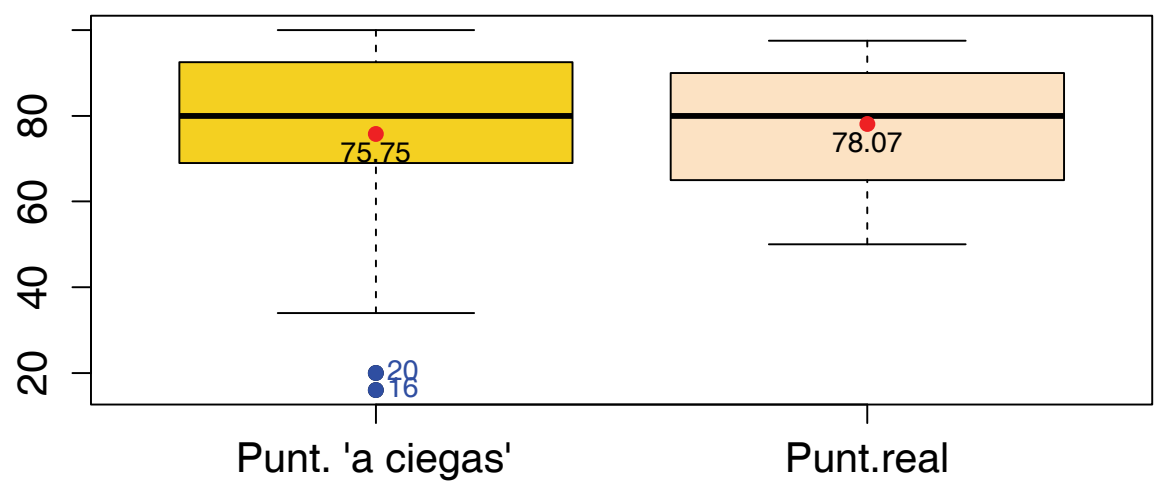

Del análisis de los datos mostrados en la figura 1 se puede afirmar que la valoración por competencias permite una mayor sensibilidad, especialmente en las puntuaciones extremas. Las mayores discrepancias entre las dos distribuciones se dan con respecto a las peores calificaciones obtenidas por los estudiantes analizados, aunque también pueden observarse algunas diferencias en las puntuaciones más elevadas.

Una vez evaluados los TFG, según el grado de adquisición de competencias, se procedió a agrupar las puntuaciones obtenidas en cinco grandes bloques: Planificación (Planif, Organización (Organiz.), Contribución (Contrib.), Conocimiento y Comunicación Oral y Escrita (Comunic_O_E). Se obtiene una matriz de datos de dimensión $44 \times 5$, sobre la que se lleva a cabo un análisis multivariable de componentes principales (ACP), con el objeto de estudiar cómo se comportan las calificaciones finales en relación con el tipo de competencia adquirida. 
Figura 3. Biplot-graph obtenido a partir de las dos primeras componentes del ACP (Variabilidad explicada por las dos primeras componentes $=0.8475$ ).

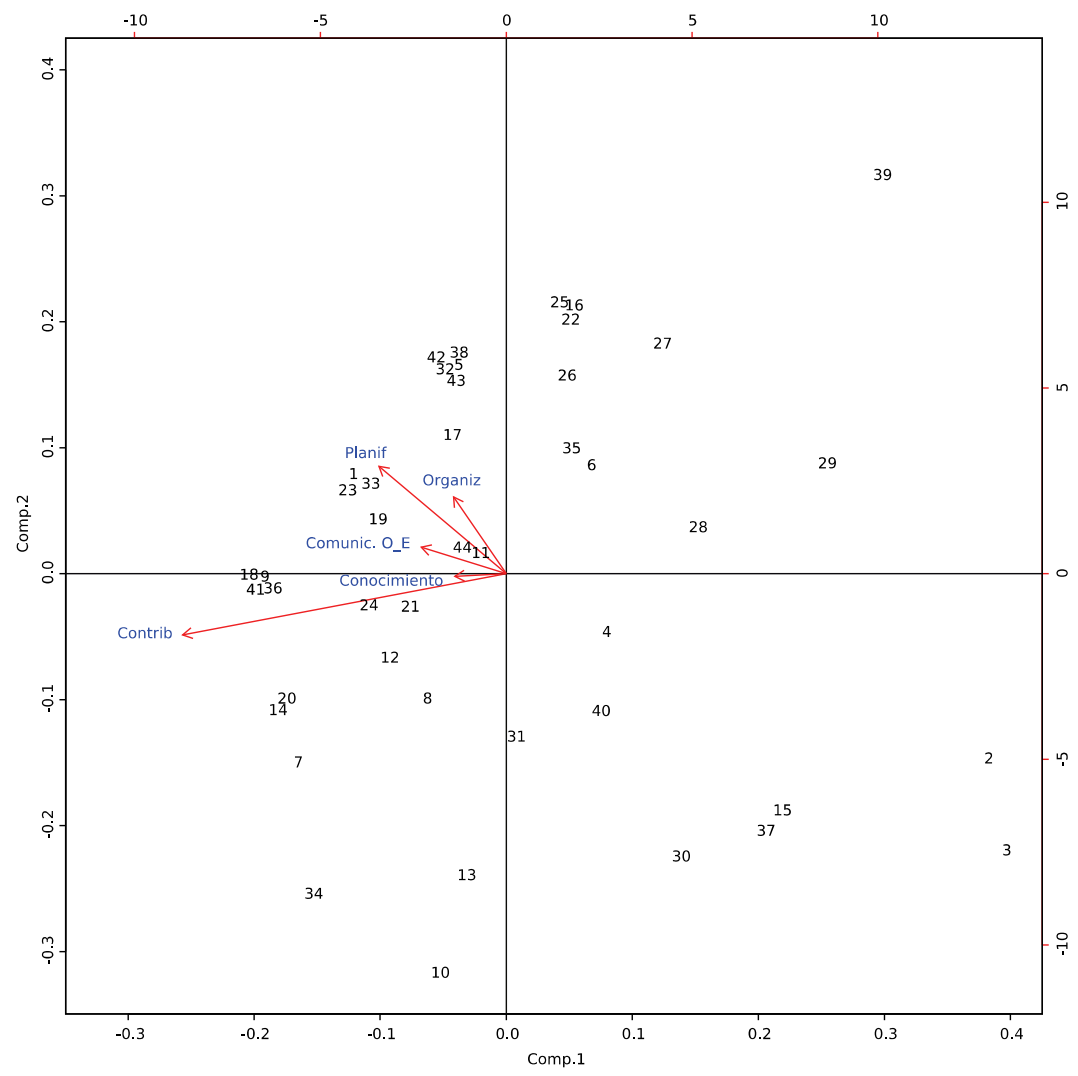

En la figura 3, se presenta el biplot graph con las dos primeras componentes del análisis, que acumulan el $84,75 \%$ de la variabilidad total de los datos. La matriz de cargas se presenta en la tabla 2.

Tabla II. Pesos del PCA

\begin{tabular}{cccccc} 
& Comp.1 & Comp.2 & Comp.3 & Comp.4 & Comp.5 \\
\hline Planif & -0.348 & 0.726 & 0.485 & -0.340 & -- \\
Organiz & -0.144 & 0.519 & -0.379 & 0.729 & -0.189 \\
Contrib & -0.886 & -0.414 & 0.110 & 0.179 & -- \\
Conocim. & -0.141 & -- & -0.421 & -0.437 & -0.782 \\
Comunic. & -0.232 & 0.179 & -0.657 & -0.361 & 0.593 \\
E_O & & & & & \\
\hline
\end{tabular}


Los pesos de las dos primeras componentes se representan mediante flechas en la figura 3. Dado que las cargas de la primera componente tienen todas el mismo signo, ello indica que esta componente se comporta como una medida de "tamaño" global. En este caso podemos interpretar que dicha medida discrimina a los individuos en función de la calificación global obtenida. A la derecha del gráfico se sitúan los estudiantes con puntuaciones bajas, mientras que los que las tienen altas lo hacen a la izquierda (véase además fig. 1). Podemos destacar la nube de puntos situados más a la izquierda y que se corresponde con individuos que han adquirido competencias en todas sus dimensiones. En la primera componente, es el bloque de competencias relativas a la contribución personal del alumno al que aporta un mayor peso discriminatorio $(-0,886)$.

Por otro lado, la segunda componente puede entenderse como una medida de la "forma" de los datos, de modo que en la parte positiva del eje se sitúan los estudiantes que han obtenido una calificación con un mayor peso en los aspectos formales del TFG (planificación y organización), mientras que las situadas en la parte negativa del eje hacen referencia a individuos con un mayor grado de competencia adquirido a través de la contribución personal.

Por último, quisiéramos señalar que el conjunto de competencias relacionadas con los conocimientos adquiridos a lo largo de la titulación son los que menos influyen en la calificación del TFG (menores pesos y menor longitud del vector que lo representa en la figura 3). De igual modo las competencias relacionadas con la Comunicación Oral y Escrita, representan una carga menor en ambas componentes, lo que no debe llamar la atención puesto que constituye el grupo de competencias más novedosas en las titulaciones de Grado y a las que los profesores están menos acostumbrados a valorar.

De nuestro análisis cuantitativo se dedujo la necesidad de desarrollar mecanismos que permitieran evaluar los trabajos con parámetros más objetivos y con criterios más unitarios para poder verificar con rigor la adquisición de cada una de las competencias que deben estar presentes en los TFG.

Se decidió, por tanto, elaborar una serie de herramientas que sirvieran por una parte, para mejorar y potenciar estas capacidades; y, por otra, para dotar a los tutores y a los tribunales de instrumentos objetivos, en la medida de lo posible, que facilitarán su evaluación de forma más homogénea y más fiable. Antes de su aplicación, solo se pedía un guión del trabajo y se llevaba a cabo una corrección secuencial de las partes del texto hasta su redacción definitiva, mecanismo que no era, a raíz de los resultados, el más conveniente. La calificación se obtenía sin aplicar criterios unitarios. Los TFGs adolecían de muchas carencias no siempre detectadas o corregidas, y los profesores que evaluaban los trabajos solo lo podían hacer de modo subjetivo. 


\section{HERRAMIENTAS DE AYUDA, SEGUIMIENTO Y EVALUACIÓN}

Se pretendió conseguir tres objetivos diferentes pero interrelacionados. En primer lugar, ayudar a los estudiantes a elaborar el TFG. En segundo, verificar que el alumno adoptara una actitud crítica y consciente hacia la temática elegida y regular un ritmo de seguimiento de los trabajos emprendidos. Por último, diseñar un procedimiento de evaluación, que conocido de antemano por los estudiantes y los profesores, guiara también la propia realización del TFG.

Para lograr el fin propuesto, desarrollamos, como ya se ha señalado, tres herramientas diferentes: un manual para el alumno, un plan de avances y, por último, una rúbrica (matriz de evaluación). El primero, ofrece al estudiante una guía clara y precisa de cómo elaborar el trabajo. El segundo, ha permitido desarrollar un procedimiento claro y unitario para todos los estudiantes y realizar un seguimiento adecuado de los avances de los alumnos con plazos temporales determinados. El tercero, la rúbrica, ha facilitado una herramienta coherente y objetiva de calificación para los tribunales que los evalúan. Permiten, tanto a los profesores como a los alumnos, realizar un seguimiento adecuado de los trabajos y una evaluación coherente y objetiva para todos ellos. Analizamos, a continuación, cada uno de ellos.

\subsection{MANUAL DEL TRABAJO DE FIN DE GRADO}

La implantación del TFG puso de manifiesto que el alumno se siente desorientado al acometer su trabajo y no sabe cómo empezar, cómo continuar, ni cómo concluir. Se enfrentan a una hoja en blanco para la que piensan que no disponen de suficientes recursos y destrezas. En otras áreas de conocimiento también se detectaron los mismos problemas. Por ejemplo, un estudio piloto en Ciencias de la Salud revela que los alumnos tienen dificultades metodológicas a la hora de diseñar los TFG (Meneses Monroy, 2011). El manual les enseña cómo utilizar lo que ya han aprendido, como usar las fuentes informativas para aprender lo que no saben. En definitiva, dota de seguridad a lo que hacen, mostrándoles el camino que deben seguir.

El manual está disponible en la plataforma educativa en formato pdf y en formato html. Contiene, en un lenguaje sencillo y cercano, toda la información que necesita para llevarlo a cabo. Contempla los aspectos más importantes en relación con los procedimientos de entrega y seguimiento del TFG, así como lo relacionado con la elección del tema, su estructura, metodología, redacción y uso ético de la información. Se les proporciona también una bibliografía básica para que puedan: concretar su trabajo, conocer métodos y formas de investigación en el Área (Beck 2008), estar al tanto de las fuentes de información y aprender a evaluarlas, redactar y utilizar el español correctamente y utilizar un gestor bibliográfico. 


\subsection{PLAN DE AVANCES}

En todo trabajo académico es necesario planificar y esto es lo que suele costar más trabajo y confusión al estudiante (Robinson et al., 2000). Por esta razón, se ha programado la entrega de dos documentos previos a la presentación final del TFG. Estos documentos que hemos denominado Avances son secuenciales y obligatorios para poder presentar el trabajo definitivo.

El primero, es, fundamentalmente, una propuesta inicial que sirva tanto para poner en claro las ideas del alumno, como para que los profesores-tutores, puedan valorar si el trabajo propuesto tiene viabilidad. El alumno debe ser capaz de expresar de forma concisa, en una o dos páginas, las razones del tema de su elección; determinar, además, qué recursos va a necesitar; presentar una bibliografía básica comentada; identificar los conocimientos que tiene; y estimar, a través de un cronograma, el tiempo que le llevará realizarlo...

En relación con los aspectos formales y de contenido, el Avance 1 es un primer indicador de la capacidad del estudiante para afrontar un trabajo académico, es decir, de su capacidad de expresión escrita, de síntesis, análisis y contextualización del tema elegido (Torrance et al., 1994; Piolat and Poussey, 1996).

Estos avances tienen su rúbrica o matriz correspondiente que el tutor debe cumplimentar y que los alumnos tienen a su disposición al inicio de la asignatura. A continuación se detallan los aspectos que contienen.

El avance 2 es un informe de progreso. Por un lado, se trata de determinar en qué medida se ha cumplido lo propuesto en el Avance 1. Y por otro, establecer qué tareas y aspectos del TFG quedan aún por cumplimentar. Al estudiante le sirve para valorar en qué situación exacta se encuentra la elaboración del TFG, y si existe la posibilidad real de terminarlo con éxito en el plazo previsto. Para el profesor-tutor, es una oportunidad excelente para revisar lo escrito, ofrecer las últimas sugerencias y determinar si el TFG está lo suficientemente maduro para afrontar la entrega final, así como su presentación y defensa ante el tribunal correspondiente. Junto con el Avance 2, el estudiante debe entregar una versión completa de su trabajo final que servirá para que el profesor tutor haga una valoración de la calidad global del trabajo, de su grado de cumplimiento, y tenga una perspectiva clara de las expectativas reales de finalización del trabajo por parte del estudiante.

\subsection{RÚBRICA (MATRIZ DE EVALUACIÓN)}

En la legislación española relativa a la ordenación de las enseñanzas oficiales de Grado (España, 2010), se establece en su artículo 12, que el TFG debe estar orientado a la "evaluación de las competencias asociadas al título". La Universidad Carlos III (2010), como ya se ha señalado, ha definido un conjunto de 
16 competencias. Sin embargo, no ha definido los mecanismos que deben aplicarse para su correcta evaluación. Cada titulación debe elaborar los sistemas necesarios para poder llevarla a cabo. La evaluación por competencias es un proceso complejo difícil de realizar en el transcurso de los estudios. Sin embargo, con el TFG el alumno puede demostrar que las ha conseguido en su totalidad (Rullán Ayza, 2010).

Para ello, es imprescindible elaborar un instrumento normalizado y lo más explicito posible, que permita valorar el grado en que los estudiantes adquieren tales competencias. Tanto los estudiantes como los profesores tutores conocen desde el comienzo la rúbrica de evaluación. Está disponible para los alumnos en la plataforma docente, de esta forma conocen, antes de comenzar el TFG, las competencias que deben alcanzar, qué parámetros van a utilizarse para su valoración y cómo se van a calificar. El proceso, por tanto, es transparente para todos (Bers, 2001).

La matriz (Tablas 3-6) recoge las 16 competencias presentes en la normativa y se utiliza en los tribunales de para evaluar todos los TFG que defiendan los estudiantes del Grado en Información y Documentación. Para que la valoración sea efectiva, las competencias se han agrupado en cinco grandes categorías, cada una de las cuales pondera, con un peso diferente, en la calificación final obtenida. Estas son:

1) Planificación y desarrollo del trabajo (25\%)

2) Organización y estructura del trabajo (10\%)

3) Contribución personal del alumno (25\%)

4) Conocimientos demostrados $(25 \%)$

5) Presentación y defensa oral (15\%).

A continuación describimos con más detalle cada una de ellas.

En la primera categoría denominada planificación y desarrollo (Tabla III), que supone el $25 \%$, el alumno debe demostrar que el trabajo ha sido planificado, se lee con facilidad y se identifican fácilmente los aspectos claves. Además debe reflejar que el problema abordado está correctamente planteado y definido; se relaciona con un marco conceptual construido en base a una revisión del estado de la cuestión con fuentes pertinentes, solventes y reputadas. Asimismo, la metodología empleada debe describirse con precisión y responder al objetivo del trabajo. 
Tabla III. Rúbrica. Categoría: Planificación y Desarrollo del trabajo

\begin{tabular}{|c|c|c|c|c|c|}
\hline TFG & $\begin{array}{l}\text { Competencias } \\
\text { generales }\end{array}$ & Puntuación: 1 & Puntuación: 2 & Puntuación: 3 & Puntuación: 4 \\
\hline \multirow{3}{*}{ 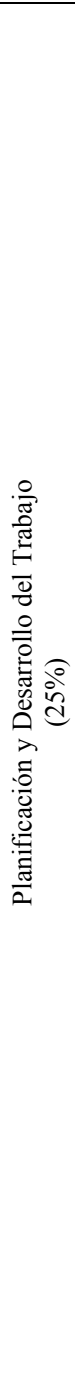 } & $\begin{array}{l}\text {-Capacidad de } \\
\text { Organizar y } \\
\text { planificar }\end{array}$ & $\begin{array}{l}\text {-No hay una línea } \\
\text { de exposición } \\
\text { ordenada ni } \\
\text { lógica. } \\
\text {-Carece de } \\
\text { planificación }\end{array}$ & $\begin{array}{l}\text {-El trabajo tiene } \\
\text { una cierta } \\
\text { estructura, pero hay } \\
\text { partes fragmentadas } \\
\text { que no se ubican } \\
\text { bien en el } \\
\text { documento. } \\
\text {-La planificación } \\
\text { no es apropiada o } \\
\text { no es suficiente }\end{array}$ & $\begin{array}{l}\text {-El trabajo } \\
\text { presenta una } \\
\text { estructura lógica, } \\
\text { ordenada, } \\
\text { incluyendo } \\
\text { introducción } \\
\text { clara con los } \\
\text { objetivos y } \\
\text { conclusiones. } \\
\text {-Planificación } \\
\text { adecuada }\end{array}$ & $\begin{array}{l}\text {-El trabajo se lee } \\
\text { con facilidad, } \\
\text { identificando } \\
\text { rápidamente los } \\
\text { aspectos clave. } \\
\text {-La planificación } \\
\text { es excelente }\end{array}$ \\
\hline & $\begin{array}{l}\text {-Elección del marco } \\
\text { conceptual adecuado } \\
\text { para la resolución de } \\
\text { un problema. }\end{array}$ & $\begin{array}{l}\text {-La descripción } \\
\text { del estado de la } \\
\text { cuestión se ha } \\
\text { realizado a partir } \\
\text { de datos y } \\
\text { opiniones de } \\
\text { fuentes no } \\
\text { solventes, sin } \\
\text { contrastar. } \\
\text {-El planteamiento } \\
\text { que se intenta } \\
\text { abordar está mal } \\
\text { descrito: no está } \\
\text { bien definido o no } \\
\text { se ha justificado } \\
\text { su necesidad }\end{array}$ & $\begin{array}{l}\text {-La descripción de } \\
\text { estado de la } \\
\text { cuestión incluye } \\
\text { algunos datos, } \\
\text { conclusiones y } \\
\text { opiniones de } \\
\text { fuentes solventes, } \\
\text { pero se mezclan } \\
\text { con datos de } \\
\text { fuentes no } \\
\text { solventes, sin } \\
\text { contrastar. } \\
\text { Se describe el } \\
\text { problema que se } \\
\text { intenta abordar } \\
\text { pero no se justifica } \\
\text { suficientemente que } \\
\text { no esté ya resuelto } \\
\text { o no se analiza el } \\
\text { problema desde } \\
\text { todas las } \\
\text { perspectivas }\end{array}$ & $\begin{array}{l}\text {-La descripción } \\
\text { de estado de la } \\
\text { cuestión incluye } \\
\text { algunos datos, } \\
\text { conclusiones y } \\
\text { opiniones de } \\
\text { fuentes solventes, } \\
\text { pero no abarca el } \\
\text { estado actual del } \\
\text { ámbito de } \\
\text { investigación, } \\
\text { bien porque } \\
\text { falten referencias } \\
\text { relevantes o bien } \\
\text { porque haya } \\
\text { temas que no se } \\
\text { hayan abordado. } \\
\text {-El problema que } \\
\text { se aborda está } \\
\text { bien planteado }\end{array}$ & $\begin{array}{l}\text {-La descripción } \\
\text { de estado de la } \\
\text { cuestión incluye } \\
\text { datos, } \\
\text { conclusiones y } \\
\text { opiniones de } \\
\text { fuentes solventes } \\
\text { y reputadas en el } \\
\text { ámbito de la } \\
\text { investigación. } \\
\text {-El problema que } \\
\text { se aborda está } \\
\text { muy bien } \\
\text { planteado, } \\
\text { definido y } \\
\text { relacionado con } \\
\text { el marco } \\
\text { conceptual }\end{array}$ \\
\hline & $\begin{array}{l}\text {-Aplicación de } \\
\text { métodos } \\
\text { cuantitativos y } \\
\text { cualitativos } \\
\text { apropiados a los } \\
\text { datos disponibles o } \\
\text { familiaridad para la } \\
\text { obtención de datos a } \\
\text { través de trabajo de } \\
\text { campo }\end{array}$ & $\begin{array}{l}\text {-El trabajo carece } \\
\text { de aspectos } \\
\text { metodológicos. }\end{array}$ & $\begin{array}{l}\text {-La metodología } \\
\text { está descrita de } \\
\text { forma ambigua y } \\
\text { parcial. }\end{array}$ & $\begin{array}{l}\text {-Se presentan } \\
\text { aspectos } \\
\text { metodológicos } \\
\text { apropiados, pero } \\
\text { se hace necesaria } \\
\text { una formulación } \\
\text { global }\end{array}$ & $\begin{array}{l}\text {-La metodología } \\
\text { está descrita con } \\
\text { precisión y } \\
\text { resulta pertinente } \\
\text { al objetivo del } \\
\text { trabajo. }\end{array}$ \\
\hline
\end{tabular}

En la segunda, relacionada con la organización y estructura (Tabla IV), cuyo valor es el $10 \%$, el estudiante debe demostrar preocupación por el trabajo bien hecho, cuidando la edición del texto, empleando figuras y tablas explicativas necesarias para su comprensión y evitando lo superfluo. Se evalúa especialmente el empleo de tecnologías de la información tanto en la búsqueda, manejando bases 
de datos factuales y bibliográficas, como en su uso y presentación, utilizando adecuadamente normas internacionales y gestores bibliográficos personales.

La tercera, que supone el $25 \%$ de la calificación final, está dedicada a la contribución personal del estudiante (Tabla V). Debe demostrar que ha adquirido las capacidades necesarias de síntesis, análisis, abstracción y deducción que le permiten elaborar conceptos propios y llegar a conclusiones pertinentes. Tiene que ser capaz de adaptarse de modo creativo a nuevas situaciones, planteando enfoques originales y poner de manifiesto que puede aplicar los conocimientos y habilidades básicos que ha adquirido a lo largo de sus estudios. También contextualizará su trabajo en un marco social, económico y medio ambiental. Además, debe contemplar compromisos éticos en el marco de buenas prácticas profesionales.

Evidentemente, en el TFG han de hacerse constar sólidos conocimientos (Tabla VI) sobre el tema desarrollado, a lo que se dedica la cuarta categoría (25\%). Será necesario que muestre una actitud crítica hacia lo aprendido permitiéndole mejorar su formación, así como demostrar cierta capacidad para aplicar los conocimientos adquiridos en situaciones y escenarios diferentes.

Por último, se evalúan competencias relacionadas con la defensa oral del trabajo (Tabla VI), que supone el $15 \%$. Esta ha sido una de las mayores novedades a la que los estudiantes deben enfrentarse actualmente. Durante décadas ha sido una práctica poco habitual en el ámbito de la educación superior en España en la que predominaban las pruebas escritas. El objetivo es valorar si los estudiantes han sido capaces de adquirir destrezas de expresión oral demostrando que son capaces de mantener la atención del tribunal, con un tono en la exposición que demuestra seguridad y soltura, siguiendo una estructura lógica en la que se hace hincapié en los puntos relevantes.

Finalmente, en la rúbrica que se emplea para la calificación, cada uno de estos grupos evaluables se ha desagregado por competencias específicas, cada una de las cuales se valora en una escala de 1 a 4 . En cada uno de los niveles se señala pormenorizadamente, los diferentes grados de adquisición. Para su elaboración se han tomado como referente, entre otras, las rúbricas realizadas por la Escuela Politécnica de la Universidad Carlos III (2010) y la de la Universidad de Virginia (University of Virginia, 2006; 2009).

A partir de esta matriz cada uno de los tres miembros del tribunal evalúa el grado

de cumplimiento de cada una de las competencias. La nota final que obtiene el estudiante es el resultado de la media de todas las evaluaciones en cada uno de los grupos de competencias. El resultado final de la calificación es la media de todas ellas. 
Tabla IV. Rúbrica. Categoría: Organización/Estructura

\begin{tabular}{|c|c|c|c|c|c|}
\hline TFG & $\begin{array}{c}\text { Competencias } \\
\text { generales }\end{array}$ & Puntuación: 1 & Puntuación: 2 & Puntuación: 3 & Puntuación: 4 \\
\hline \multirow[b]{2}{*}{ 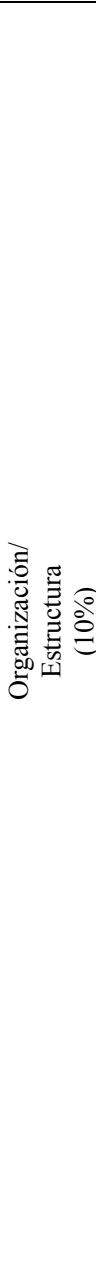 } & $\begin{array}{l}\text {-Preocupación por } \\
\text { la calidad y el } \\
\text { trabajo bien hecho }\end{array}$ & $\begin{array}{l}\text {-El texto tiene } \\
\text { abundantes faltas } \\
\text { gramaticales, } \\
\text { ortográficas y } \\
\text { sintácticas. } \\
\text {-La edición es } \\
\text { irregular y } \\
\text { descuidada } \\
\text {-Las figuras/gráficos } \\
\text { son de mala calidad y } \\
\text { no apoyan la } \\
\text { comprensión del } \\
\text { texto }\end{array}$ & $\begin{array}{l}\text {-La edición del } \\
\text { texto es } \\
\text { mejorable en } \\
\text { algunas partes. } \\
\text { Se aprecian } \\
\text { algunos errores } \\
\text { de ortografía } \\
\text { técnica. } \\
\text {-Las figuras son } \\
\text { buenas, pero } \\
\text { están mal } \\
\text { ubicadas, y } \\
\text { apoyan } \\
\text { parcialmente la } \\
\text { compresión del } \\
\text { texto }\end{array}$ & $\begin{array}{l}\text {-La edición del } \\
\text { texto es adecuada } \\
\text { y pertinente. } \\
\text { Apenas hay } \\
\text { errores } \\
\text { ortográficos. } \\
\text {-Las figuras son } \\
\text { de calidad, y } \\
\text { ayudan a la } \\
\text { compresión del } \\
\text { texto }\end{array}$ & $\begin{array}{l}\text {-La edición del texto } \\
\text { está muy cuidada } \\
\text { Se cumplen los } \\
\text { requisitos formales } \\
\text { de edición } \\
\text {-Las figuras son de } \\
\text { calidad, y son auto } \\
\text { explicativas, } \\
\text { permitiendo } \\
\text { comprender } \\
\text { conceptos } \\
\text { relacionados con el } \\
\text { trabajo por sí mismas }\end{array}$ \\
\hline & $\begin{array}{l}\text {-Uso de las nuevas } \\
\text { tecnologías para la } \\
\text { búsqueda de } \\
\text { información y } \\
\text { documentación y } \\
\text { de datos } \\
\text { estadísticos }\end{array}$ & $\begin{array}{l}\text {-No se aprecia el uso } \\
\text { de nuevas tecnologías } \\
\text { para la búsqueda de } \\
\text { información. } \\
\text {-No presenta } \\
\text { bibliografía o es } \\
\text { escasa y poco } \\
\text { pertinente. } \\
\text {-No se mencionan } \\
\text { otras fuentes } \\
\text { necesarias de datos. } \\
\text {-Citas bibliográficas } \\
\text { sin normalizar }\end{array}$ & $\begin{array}{l}\text {-No se aprecia el } \\
\text { uso de nuevas } \\
\text { tecnologías para } \\
\text { la búsqueda de } \\
\text { información. } \\
\text {-La bibliografía } \\
\text { es escasa. } \\
\text {-La bibliografía } \\
\text { no está } \\
\text { actualizada y/o } \\
\text { es demasiado } \\
\text { genérica. } \\
\text {-Se emplean } \\
\text { oras fuentes de } \\
\text { datos y } \\
\text { documentación } \\
\text { pero no se } \\
\text { referencian } \\
\text { adecuadamente } \\
\text {-Citas } \\
\text { bibliográficas } \\
\text { normalizadas } \\
\text { pero no de } \\
\text { forma uniforme }\end{array}$ & $\begin{array}{l}\text {-Se aprecia un uso } \\
\text { adecuado de } \\
\text { tecnologías para la } \\
\text { búsqueda de } \\
\text { información. } \\
\text {-No usa } \\
\text { adecuadamente la } \\
\text { información, a } \\
\text { través de las citas } \\
\text { y referencias } \\
\text { bibliográficas } \\
\text {-La bibliografía es } \\
\text { adecuada y está } \\
\text { actualizada } \\
\text {-Citas } \\
\text { bibliográficas } \\
\text { normalizadas y } \\
\text { uniformes. } \\
\text {-No se aprecia el } \\
\text { empleo de un } \\
\text { gestor } \\
\text { bibliográfico } \\
\text { personal }\end{array}$ & $\begin{array}{l}\text {-Se aprecia el uso de } \\
\text { tecnologías de la } \\
\text { información tanto en } \\
\text { la búsqueda como en } \\
\text { su uso y } \\
\text { presentación. } \\
\text {-Usa adecuadamente } \\
\text { la información, a } \\
\text { través de las citas y } \\
\text { referencias } \\
\text { bibliográficas. } \\
\text {-Queda manifiesto el } \\
\text { empleo de un gestor } \\
\text { bibliográfico } \\
\text { personal }\end{array}$ \\
\hline
\end{tabular}


Tabla V. Rúbrica. Categoría Contribución del estudiante

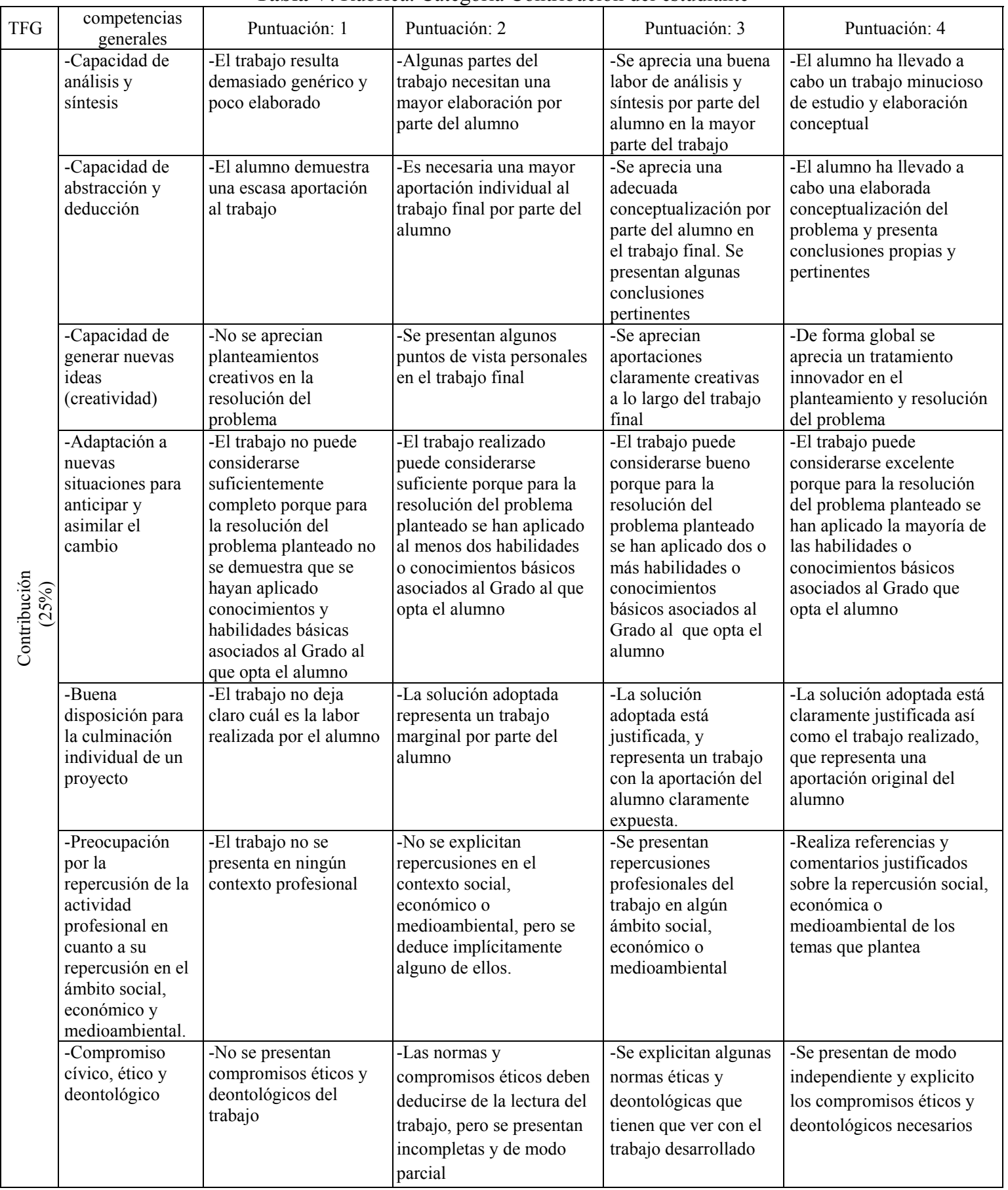


Tabla 6. Rúbrica. Categorías: Conocimientos y Presentación, defensa y tono de la exposición

\begin{tabular}{|c|c|c|c|c|c|}
\hline TFG & $\begin{array}{c}\text { Competencias } \\
\text { generales }\end{array}$ & Puntuación: 1 & Puntuación: 2 & Puntuación: 3 & Puntuación: 4 \\
\hline \multirow[t]{2}{*}{ 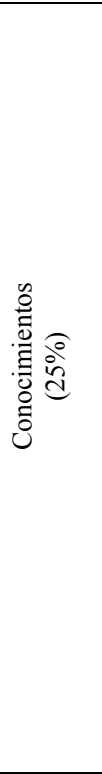 } & $\begin{array}{l}\text {-Actitud crítica } \\
\text { respecto a } \\
\text { conocimientos } \\
\text { actuales }\end{array}$ & $\begin{array}{l}\text {-El alumno demuestra } \\
\text { que no tiene } \\
\text { suficientes } \\
\text { conocimientos. } \\
\text { Carece de actitud } \\
\text { crítica. Y no sabe } \\
\text { responder al Tribunal } \\
\text { sobre su trabajo }\end{array}$ & $\begin{array}{l}\text {-El alumno } \\
\text { demuestra un } \\
\text { conocimiento } \\
\text { básico del trabajo } \\
\text { desarrollado. Pero } \\
\text { no puede realizar } \\
\text { una argumentación } \\
\text { propia. Y no es } \\
\text { capaz de responder } \\
\text { a las preguntas del } \\
\text { tribunal }\end{array}$ & $\begin{array}{l}\text {-El alumno } \\
\text { demuestra que el } \\
\text { trabajo le ha } \\
\text { proporcionado } \\
\text { buenos } \\
\text { conocimientos } \\
\text { sobre el tema. } \\
\text { Argumenta } \\
\text { correctamente sus } \\
\text { propios puntos de } \\
\text { vista. Y es capaz } \\
\text { de responder al } \\
\text { tribunal aportando } \\
\text { datos adicionales }\end{array}$ & $\begin{array}{l}\text {-El alumno } \\
\text { demuestra que tiene } \\
\text { un sólido } \\
\text { conocimiento del } \\
\text { tema. Examina y } \\
\text { ahonda en la materia } \\
\text { obteniendo sus } \\
\text { propias conclusiones. } \\
\text { Y es capaz de utilizar } \\
\text { las preguntas del } \\
\text { Tribunal para } \\
\text { reflejarlo }\end{array}$ \\
\hline & $\begin{array}{l}\text {-Aplicación de los } \\
\text { conocimientos a } \\
\text { situaciones diversas } \\
\text { y en escenarios } \\
\text { diversos }\end{array}$ & $\begin{array}{l}\text {-El alumno no } \\
\text { demuestra haber } \\
\text { conseguido las } \\
\text { habilidades o } \\
\text { conocimientos } \\
\text { básicos asociados al } \\
\text { Grado que opta }\end{array}$ & $\begin{array}{l}\text {-El alumno parece } \\
\text { haber conseguido } \\
\text { algunas habilidades } \\
\text { o conocimientos } \\
\text { básicos asociados al } \\
\text { Grado que opta } \\
\text { pero no muestra la } \\
\text { necesaria seguridad } \\
\text { en los mismos }\end{array}$ & \begin{tabular}{|l}
-El alumno ha \\
conseguido \\
algunas \\
habilidades o \\
conocimientos \\
básicos asociados \\
al Grado que opta \\
y muestra \\
seguridad en los \\
mismos \\
\end{tabular} & $\begin{array}{l}\text {-El alumno no sólo } \\
\text { parece haber } \\
\text { conseguido todas las } \\
\text { habilidades o } \\
\text { conocimientos } \\
\text { básicos asociados al } \\
\text { Grado que opta sino } \\
\text { que el trabajo le ha } \\
\text { permitido mejorar su } \\
\text { formación } \\
\end{array}$ \\
\hline \multirow[t]{2}{*}{ 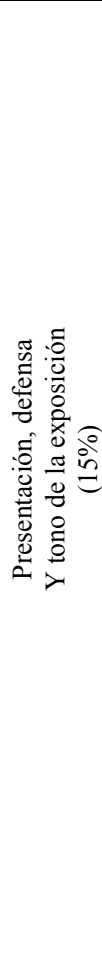 } & $\begin{array}{l}\text {-Dominio del } \\
\text { lenguaje y disciplina } \\
\text { en su uso para un } \\
\text { adecuado ejercicio } \\
\text { de la comunicación } \\
\text { oral y escrita }\end{array}$ & $\begin{array}{l}\text {-La exposición es } \\
\text { pobre, aburrida y no } \\
\text { contiene información } \\
\text { relevante. No se sigue } \\
\text { una línea de } \\
\text { exposición apropiada. } \\
\text {-No hace uso de } \\
\text { medios informáticos } \\
\text { para la defensa del } \\
\text { trabajo }\end{array}$ & $\begin{array}{l}\text {-La exposición } \\
\text { intenta a veces } \\
\text { atraer la atención } \\
\text { del tribunal, en } \\
\text { aspectos relevantes } \\
\text { del trabajo, pero no } \\
\text { tiene una línea } \\
\text { continua de } \\
\text { exposición. } \\
\text {-Utiliza medios } \\
\text { informáticos para la } \\
\text { defensa del Trabajo, } \\
\text { pero son pobres y, a } \\
\text { presentación es } \\
\text { pobre y no añade } \\
\text { valor a la defensa }\end{array}$ & $\begin{array}{l}\text {-La exposición es } \\
\text { interesante, } \\
\text { mantiene la } \\
\text { atención del } \\
\text { tribunal, siguiendo } \\
\text { una estructura } \\
\text { lógica de } \\
\text { exposición que } \\
\text { toca los puntos } \\
\text { relevantes. } \\
\text {-Maneja } \\
\text { correctamente los } \\
\text { medios } \\
\text { informáticos para } \\
\text { la presentación del } \\
\text { trabajo } \\
\text { resaltándola }\end{array}$ & $\begin{array}{l}\text {-La exposición es } \\
\text { muy interesante, } \\
\text { mantiene en todo } \\
\text { momento la atención } \\
\text { del tribunal, } \\
\text { siguiendo una } \\
\text { estructura lógica de } \\
\text { exposición que toca } \\
\text { los puntos relevantes } \\
\text { y hace uso de } \\
\text { presentaciones } \\
\text { adecuadas y } \\
\text { enriquecedoras. }\end{array}$ \\
\hline & $\begin{array}{l}\text {-Desarrollo de } \\
\text { habilidades de } \\
\text { aprendizaje y grado } \\
\text { de confianza y } \\
\text { autonomía } \\
\text { adquiridos }\end{array}$ & $\begin{array}{l}\text {-El tono es muy bajo } \\
\text { para ser percibido con } \\
\text { claridad, con pausas } \\
\text { largas de espera, y } \\
\text { saltos bruscos entre } \\
\text { slides por perdida del } \\
\text { hilo de exposición. } \\
\text { El lenguaje corporal } \\
\text { no es adecuado }\end{array}$ & $\begin{array}{l}\text {-El tono es bajo } \\
\text { pero lo sube cuando } \\
\text { es indicado. Habla } \\
\text { con visibles signos } \\
\text { de incomodidad, } \\
\text { pero sigue el hilo } \\
\text { conductor de las } \\
\text { slides con leves } \\
\text { momentos de } \\
\text { titubeo. } \\
\text {-El lenguaje } \\
\text { corporal es } \\
\text { inexpresivo }\end{array}$ & $\begin{array}{l}\text {-El tono es } \\
\text { adecuado durante } \\
\text { la presentación, y } \\
\text { sigue el hilo } \\
\text { conductor de las } \\
\text { diapositivas o del } \\
\text { medio en que se } \\
\text { apoye sin } \\
\text { problema. } \\
\text {-El lenguaje } \\
\text { corporal es } \\
\text { adecuado }\end{array}$ & $\begin{array}{l}\text {-El alumno realiza } \\
\text { una presentación con } \\
\text { seguridad, } \\
\text { dirigiéndose hacia el } \\
\text { tribunal y la } \\
\text { audiencia en la sala, } \\
\text { y manejando la } \\
\text { presentación con } \\
\text { soltura. } \\
\text {-El lenguaje corporal } \\
\text { es excelente }\end{array}$ \\
\hline
\end{tabular}




\section{RESULTADOS Y CONCLUSIONES}

El manual, los avances y la rúbrica de evaluación comenzaron a utilizarse en el curso 2010-2011. Desde entonces, se han venido aplicando a todos los TFGs defendidos, tanto de alumnos del Curso de Adaptación al Grado como del Grado. Evidentemente, aunque habrá que realizar una valoración pormenorizada de estos para sacar conclusiones determinantes, sí podemos adelantar la utilidad de estas herramientas con la experiencia de los 44 TFGs evaluados en este trabajo.

En líneas generales, los resultados obtenidos han sido satisfactorios. Los TFGs defendidos mejoraron en su estructura, los temas elegidos están justificados coherentemente y enmarcados en una visión de conjunto de la profesión, así como en los conocimientos que demuestran. En definitiva, los alumnos son más conscientes ahora de lo que se espera de ellos y de las competencias que deben alcanzar, esto redunda, sin duda alguna en la calidad de los trabajos que presentan.

Los estudiantes han manifestado que estas herramientas les permiten tener una guía clara de los procedimientos que deben seguir para superar con éxito su trabajo. El manual les orienta en su realización, los avances les permiten conocer, en cada momento, cómo evoluciona su trabajo y los plazos que deben cumplir para defenderlo en la fecha deseada. Por otra parte, la mayoría de los profesores piensan que tener herramientas unificadas para el seguimiento y la evaluación del los TFG proporciona una mayor consistencia al proceso.

Finalizamos el trabajo exponiendo, a modo de conclusiones, tanto los aspectos positivos como negativos de las herramientas presentadas:

-Por lo que se refiere al manual, los alumnos cuentan ahora con un documento ad hoc para su Grado que les guía en las cuestiones fundamentales que deben abordar y les ayuda a planificar su TFG. Los profesores saben que todos los alumnos cuentan con el mismo material. Les "libera", por tanto, de repetir cuestiones básicas y pueden dedicarse más a orientar a los alumnos en los contenidos del TFG.

-Respecto a los avances, los alumnos conocen desde el inicio el tiempo del que disponen para ir avanzando en la realización del TFG de forma estructurada, lo que les permite cumplir un cronograma. Estos tiempos fijados, pueden provocar una sensación de presión continua no grata. Sin embargo, nos parece necesario marcar plazos con los que el estudiante se comprometa para la buena marcha del proceso. Por otro lado, los profesores tienen un procedimiento claro de cómo actuar y la calidad que deben exigir a los futuros graduados.

-En cuanto a la rúbrica, permite que los alumnos conozcan desde el comienzo de su trabajo las competencias que deben haber adquirido a lo largo de sus cuatro años de estudio. Son conscientes de que su labor va a ser evaluada con criterios objetivos y unitarios, independientemente de que realicen su trabajo con uno u otro profesor, los procedimientos son los mismos para todos. Este hecho les da mayor 
confianza ya que siempre tienden a pensar que la evaluación depende de la persona que pueda realizarla.

-Las calificaciones de los TFGs de los profesores que forman parte de los tribunales, son ahora más seguras y objetivas. Una de las preguntas recurrentes era saber cómo se podían medir las competencias, qué debían evaluar y cómo. La rúbrica contribuye a dotar de mayor objetividad al proceso de evaluación ya que todos los tribunales se rigen por los mismos parámetros. Lógicamente siempre hay un componente subjetivo, pero se ve altamente disminuido con la aplicación de la matriz.

-Una debilidad de la rúbrica, podría ser, que una excesiva concreción de las competencias provoque en el alumno una sensación de sobrecarga al intentar alcanzarlas todas. Puede ocasionar que el trabajo se enfoque de modo excesivamente analítico, perdiendo de vista el conjunto del trabajo. Este posible riesgo se evita con las tutorías individualizadas en las que el profesor le ayuda a entender de forma adecuada las competencias reflejadas en la matriz. Tanto profesores como alumnos deben adaptarse a la evaluación por competencias, proceso que requiere tiempo.

-Otro posible inconveniente es la resistencia que esta herramienta pudiera provocar en algunos profesores al verse excesivamente encauzados en el proceso de seguimiento y evaluación del trabajo del alumno. La sensación de intromisión en su modo de hacer y criterio de actuación, que consideran válido, se podría traducir en la percepción de pérdida de libertad docente. Esta forma de abordar el TFG, enmarcada en los cambios por la adaptación de los títulos al EEES, supone además una adaptación del profesorado a nuevos retos y rutinas que incrementan considerablemente el trabajo a realizar.

Podemos afirmar que el manual, el establecimiento y regulación de los avances, así como la creación de una rúbrica adecuada, son herramientas imprescindibles para guiar, regular y gestionar de forma clara, para todas las partes implicadas, los trabajos de fin de Grado.

Se deberá realizar un seguimiento de los TFGs en los próximos años para verificar la utilidad de estos instrumentos así como realizar las modificaciones y adaptaciones que sean necesarias.

\section{REFERENCIAS BIBLIOGRÁFICAS}

ANDRÉS, J. M. (2009). Guía para la evaluación de competencias en el trabajo de fin de grado en el ámbito de las Ciencias Sociales y Jurídicas. Barcelona: Agència per a la Qualitat del Sistema Universitari de Catalunya. http://www.aqu.cat/publicacions/guies_competencies/guia_tfg_socials_es.html. [consulta 4/3/2012].

ANECA. (2004). Libro Blanco. Titulo de Grado en Información y Documentación. Madrid: Agencia Nacional de Evaluación de la Calidad y Acreditación. 
http://www.aneca.es/var/media/150424/libroblanco_jun0"5_documentacion.pd f. [consulta $1 / 3 / 2014$ ]

BECK, S. E. \& MANUEL, K. (2008). Practical research methods for librarians and information professionals. Nueva York: Neal-Schuman.

BERS, T. H. (2001). "Measuring and Reporting Competencies". New Directions for Institutional Research, $\mathrm{n}^{\circ} 110$, pp. 29-40.

CARABAÑA MORALES, J. (2011). "Competencias y Universidad, o un desajuste por mutua ignorancia". BORDÓN, Revista de Pedagogía, vol. 63, nº. 1, pp. 15-31.

CASTRO MORERA, M. (2011). “¿Qué sabemos de la medida de las competencias? Características y problemas psicométricos en la evaluación de las competencias". BORDÓN, Revista de Pedagogía, vol. 63, nº. 1, pp. 109-123.

ESPAÑA. (2007). Real Decreto 1393/2007, de 29 de octubre, por el que se establece la ordenación de las enseñanzas universitarias oficiales. Madrid: BOE. $\quad \mathrm{http}: / / \mathrm{www} \cdot$ boe.es/boe/dias/2007/10/30/pdfs/A44037-44048.pdf. Accessed 24 January 2012 [consulta 23/4/2013]

FERNÁNDEZ DÍaz, M .J., CARBALLO SANTAOLALLA, R. \& GALÁN GONZÁLEZ, A. (2010). "Faculty attitudes and training needs to respond the new European Higher Education challenges". Higher Education, no 60, pp. 101-118.

FERRER, V. (2012). El trabajo de fin de grado: guia para estudiantes, docentes y agentes colaboradores. Madrid: McGraw-Hill Interamericana.

FONDEVILA GASCÓN, J.F. (2013). El trabajo de fin de grado en Ciencias Sociales y Jurídicas : guía metodológica. Madrid: Ediciones Internacionales Universitarias.

Foro sobre la Evaluación de la Calidad de la Investigación y de la Educación Superior (VIII) (2011). Santander: FECIES, $2011 \mathrm{http} / / / \mathrm{www} . u g r . e s / \sim a e p c /$ VIIIFORO/presentacion.html. [consulta 23/2/2014].

JORNET MELÍA, J. M. et al. (2011). "Diseño de procesos de evaluación de competencias: consideraciones acerca de los estándares en el dominio de las competencias". BORDÓN, Revista de Pedagogía, 63 (1), pp. 125-145.

KERKA, S. (1998). "Competency-Based Education and Training, Myths and Realities". ACVE Publications. http://www.calpro-online.org/eric/textonly/ docgen.asp?tbl=mr\&ID=65. [consulta $1 / 3 / 2013$ ].

MANO GONZÁLEZ, M. de la y MORO CABERO, M. (2009) “La evaluación por competencias: propuesta de un sistema de medida para el grado en Información y Documentación". BID, $\mathrm{n}^{\mathrm{o}} 23 \mathrm{http} / / / \mathrm{www} . u b . e d u / \mathrm{bid} / 23 /$ delamano2.htm. [consulta 21/3/2014].

MARTÍNEZ-BERRUEZO, M. A. y GARCÍA-VARELA, A. B. (2011) “¿Cómo cambian las estrategias de aprendizaje de los estudiantes universitarios con la adaptación metodológica al Espacio Europeo de Educación Superior?" BORDÓN, Revista de Pedagogía, no 63 (2), pp. 65-74. 
MENESES MONROY, A. (2011). El trabajo de fin de grado como evaluador de las competencias profesionales del enfermero generalista. Tesis Doctoral. Madrid: Universidad Complutense, Escuela Universitaria de Enfermería. http://eprints.ucm.es/13137/. [consulta 1/3/2013].

PAULSON, K. (2001). "An Annotated Bibliography on Competencies". New Directions for Institutional Research, $\mathrm{n}^{\circ}$ 110, pp. 97-111.

PIMIENTA PRIETO, J. H. (2011). "Secuencias didácticas: aprendizaje y evaluación de competencias en Educación Superior". BORDÓN, Revista de Pedagogía, no 63 (1), pp. 77-92.

PIOLAT, A. y POUSSEY, J.Y. (1996). "Students' writing strategies and text quality". Learning and Instruction, $\mathrm{n}^{\circ}$ 6, pp. 111-129.

R DEVELOPMENT CORE TEAM (2011). $R$ : A language and environment for statistical computing. Vienna: $R$ Foundation for Statistical Computing. URL http://www.R-project.org/. [consulta 18/6/2013].

RIBES IÑESTA, E. (2011). "El concepto de competencia: su pertinencia en el desarrollo psicológico y la educación". BORDÓN, Revista de Pedagogía, no 63 (1), pp. 33-45.

RULLÁN AYZA, M. et al. (2010). ” La evaluación de competencias transversales en la materia Trabajos Fin de Grado. Un estudio preliminar sobre la necesidad y oportunidad de establecer medios e instrumentos por ramas de conocimiento". Revista de Docencia Universitaria, $\mathrm{n}^{\mathrm{o}}$ 1, pp. 74-100. http://redaberta.usc.es/redu/index.php/REDU/article/view/146/0. [consulta $12 / 3 / 2014]$.

SALVADOR OLIVÁN, J. A. et al. (2011). "La presencia de competencias en información en los títulos de grado de la Universidad de Zaragoza". Anales de Documentación, vol. 14 (2). http://revistas.um.es/analesdoc/article/view/ 114981. [consulta 23/2/2014]

TORRANCE, M., THOMAS, G.V. y ROBINSON, E. J. (1994). "The writing strategies of graduate research students in the social sciences". Higher Education, ${ }^{\circ}$ 27, pp. 379-392.

TORRANCE, M., THOMAS, G.V. y ROBINSON, E. J. (2000). "Individual differences in undergraduate essay-writing strategies: A longitudinal study". Higher Education, $\mathrm{n}^{\circ}$ 39, pp. 181-200.

TUNING América Latina (2012). http://www.tuningal.org/. [consulta 7/3/2013].

TUNING Educational Structures in Europe (2009). http://www.unideusto.org/ tuningeu/. [ consulta 7/3/2013].

UNIVERSIDAD CARLOS III DE MADRID (2008). Normativa reguladora de proyectos de fin de carrera. http://www.uc3m.es/portal/page/portal/ organizacion/secret_general/normativa/estudiantes/estudios_grado/NORMATI VA\%20REGULADORA\%20DE\%20PROYECTOS\%20DE\%20FIN\%20DE\% 20CARRERA\%20APRO.pdf. [consulta 24/1/ 2013]. 
UNIVERSIDAD CARLOS III DE MADRID (2010). Normativa sobre la organización y evaluación de la asignatura Trabajo fin de Grado. Boletín Oficial de la Universidad Carlos III, n. 41, 10/2. http://e-archivo.uc3m.es/ bitstream/10016/10743/1/boletin_41.pdf. [consulta 24/1/2013].

UNIVERSITAT AUTÓNOMA DE BARCELONA (2010). Simposio Planificación y evaluación de Trabajos de Final del Grado: la experiencia desde Europa. Barcelona.

UNIVERSITY OF VIRGINIA. Department of Science, Technology, and Society (2006). Undergraduate Thesis Manual 2006-2007. http://www.sts.virginia.edu/ common/pdf/UTM2006-2007.pdf. [consulta 22/11/2012].

UNIVERSITY OF VIRGINIA. Department of Science, Technology, and Society (2009). Undergraduate Thesis Manual 2009-2010. http://www.sts.virginia.edu/ common/pdf/UTM2009-2010.pdf. [consulta 22/11/2012].

VALDERRAMA VALLÉS, E. (2009). Guía para la evaluación de competencias en los trabajos de fin de grado y de máster en las ingenierías. Barcelona: Agència per a la Qualitat del Sistema Universitari de Catalunya. http://www.aqu.cat/doc/doc_19718727_1.pdf. [consulta 26/1/2012].

VALDERRAMA VALLES, E., RULLAN AYZA, M., SANCHEZ, F., PONS, J., MANS, GINE, C. F., et. al. (2010). "La evaluación de competencias en los Trabajos de Fin de Grado". IEEE-RITA, $\mathrm{n}^{\mathrm{o}} 3$, pp. 107-113. http://capinfo.e.ac.upc.edu/PDFs/dir10/file003867.pdf. [consulta 26/1/2014].

VILARDELL RIERA, I. (2010). "Experiencia sobre el trabajo de fin de Grado en Administración y Dirección de Empresas". Revista de Educación en Contabilidad, Finanzas y Administración de Empresas, nº 1 (1), pp. 101-122.

VOORHEES, R. (2001). "Competency-Based Learning Models: A Necessary Future". New Directions for Institutional Research, $\mathrm{n}^{\circ}$ 110, pp. 5-13. 